\title{
The Role of Inhaled Insulin in the Management of Type 2 Diabetes
}

\author{
Wesley Nuffer, Jennifer Trujillo \\ Department of Clinical Pharmacy, University of Colorado Skaggs School of Pharmacy \& Pharmaceutical \\ Sciences, Aurora, CO, USA \\ Email: Wesley.Nuffer@ucdenver.edu
}

Received 17 March 2016; accepted 18 April 2016; published 21 April 2016

Copyright (C) 2016 by authors and Scientific Research Publishing Inc.

This work is licensed under the Creative Commons Attribution International License (CC BY). http://creativecommons.org/licenses/by/4.0/

c) (i) Open Access

\begin{abstract}
Type 2 diabetes continues to place a major burden on the health care system of the United States and worldwide. Type 2 diabetes involves two major defects: decreased insulin production from the pancreas and increased insulin resistance. Many patients with type 2 diabetes have decreased insulin production which requires exogenous insulin therapy in order to manage their disease. Despite this need, there is often a reluctance to initiate insulin therapy from both providers and patients. One reason for this reluctance may be a fear of needles or of administering injections. Delivering insulin through the lungs has been studied for decades, with the first inhaled insulin product coming to market in 2006. This product's launch was considered unsuccessful, and the product was discontinued by the manufacturer the following year. A new inhaled insulin, Technosphere ${ }^{\circledR}$ insulin, was approved for use in type 1 and type 2 diabetes in 2014. This product was shown superior to placebo and non-inferior to a premixed bi-phasic subcutaneous insulin in patients with type 2 diabetes, and may offer an alternative to patients who are averse to giving subcutaneous injections.
\end{abstract}

\section{Keywords}

Inhaled Insulin, Technosphere, Afrezza, Type 2 Diabetes

\section{Introduction}

Diabetes and its complications continue to pose a major burden to the United States (US) and the world. In 1995, the world-wide prevalence of diabetes in adults was estimated at approximately 4\%, and it was predicted that this would increase to $5.4 \%$ by the year 2025 [1]. In the US, 29.1 million people are estimated to have diabetes, with approximately 8 million of these cases remaining undiagnosed [2]. This comprises roughly $9.3 \%$ of 
the US adult population, with another estimated $37 \%$ of adults showing clinical signs of prediabetes [2]. The economic impact of this disease in the US is estimated at 245 billion dollars a year [2].

Type 2 diabetes (T2D) accounts for over $90 \%$ of the total prevalence of the disease, and is characterized by increased insulin resistance by skeletal muscle, adipose and liver cells, and decreased insulin secretion by the pancreatic beta cells, both of which lead to elevated blood glucose levels, or hyperglycemia [3]. Initially, this disease can be managed with lifestyle modifications (healthy diet, moderate exercise, and weight loss) together with one or more oral antihyperglycemic agents (OAAs), but due to its chronic, progressive nature, additional therapies are often required. The continuous loss of beta cells often leads to the need for exogenous insulin therapy in T2D patients. National clinical guidelines recommend basal insulin therapy as a possible 2nd line option for T2D treatment, with insulin intensification suggested for those patients who do not meet hemoglobin A1C (A1C) goals [4] [5]. Guidelines from the American Diabetes Association (ADA) suggest that insulin therapy may be superior to other treatment options in managing T2D, particularly as a 3rd line agent or in patients with very high A1C values ( $>9 \%$ ) [4]. Insulin therapy allows for some flexibility with therapy, as the patient can adjust their insulin dose based on food choices, glycemic targets, and the amount of activity they have performed [6] [7]. Unfortunately, there is often the resistance to initiating insulin therapy from both patients and providers, which may delay or inhibit insulin's use [8]-[10]. This resistance may be due to misconceptions or misunderstandings about insulin, or fear and anxiety about needles and self-administering injections [10] [11]. For decades, the delivery of insulin has been restricted to administration through subcutaneous injections or delivered by continuous infusion through the use of a pump device. Many researches have focused on identifying alternative, less invasive methods to deliver insulin into the body. This article reviews the evidence for pulmonary insulin delivery, with a focus on Technosphere ${ }^{\mathbb{B}}$ insulin, approved as an inhaled insulin in the US in 2014.

\section{Development of Inhaled Insulin}

Pulmonary delivery of insulin has been investigated for years, assisted by technological advances in drug delivery for the treatment of asthma. Expert opinion identifies inhaled insulin as one of the most advantageous non-invasive delivery routes [12]. Research exploring inhaled insulin dates back to shortly after insulin was discovered, in 1924 [13]. Initial absorption challenges faced with delivering insulin through the lungs were overcome through advancements in inhaler technologies in the 1990s [14]. This led to a number of companies exploring inhaled insulin products, with the first inhaled insulin becoming approved in both the US and in Europe under the tradename of Exubera ${ }^{\circledR}$ in 2006. While shown to be effective, this product was not very successful on the market, however, and was removed from the market voluntarily by Pfizer in October 2007 due to low sales [15]. There was quite a bit of speculation as to why this first inhaled insulin was unsuccessful in its market launch. Sales had been predicted at approximately two billion dollars, but the product only yielded around 12 million through the first three quarters of 2007 [15]. There were criticisms about the inhaler device being large, cumbersome, and hard to clean, the marketing strategy being possibly flawed, and difficulties in the dosing conversion, as the inhaled insulin was produced and marketed in milligrams, not units [15] [16]. Clinical guidelines at the time also did not support widespread use, citing that the cost-effectiveness of the product had not been shown, and reserving it for specific populations of patients where there may be needle phobias or other concerns [15] [16]. The poor success shown by Exubera ${ }^{\circledR}$ resulted in the discontinuation of research on another inhaled insulin product that was being developed by Eli Lilly [16]. This left one company, Mannkind Corporation, who continued research and development on their inhaled insulin product, Technosphere ${ }^{\circledR}$ insulin. This product, Technosphere ${ }^{\circledR}$ insulin, was approved for use in the United States in 2014.

\section{Technosphere Insulin-Pharmacokinetics}

Technosphere ${ }^{\circledR}$ insulin (TI) is a powdered formulation of human, recombinant DNA insulin. The product demonstrates very rapid absorption through the lungs due to a proprietary carrier molecule, fumaryldiketopiperazine (FDKP), which encapsulates the insulin into microspheres [17]. Once inhaled into the lungs, the neutral pH causes the particles to dissolve and release the insulin for absorption into circulation. Pharmacokinetic studies demonstrated time to maximum concentrations $\left(\mathrm{T}_{\max }\right.$ ) of TI being achieved in approximately 12 to 15 minutes, compared to around 40 minutes with a subcutaneous rapid acting insulin analog (RAIA) [18] [19] (Figure 1). This early absorption has been shown to suppress endogenous glucose production more quickly than other insulin preparations [18]. The maximum concentration $\left(\mathrm{C}_{\max }\right)$ of insulin following TI inhalation was also shown to 


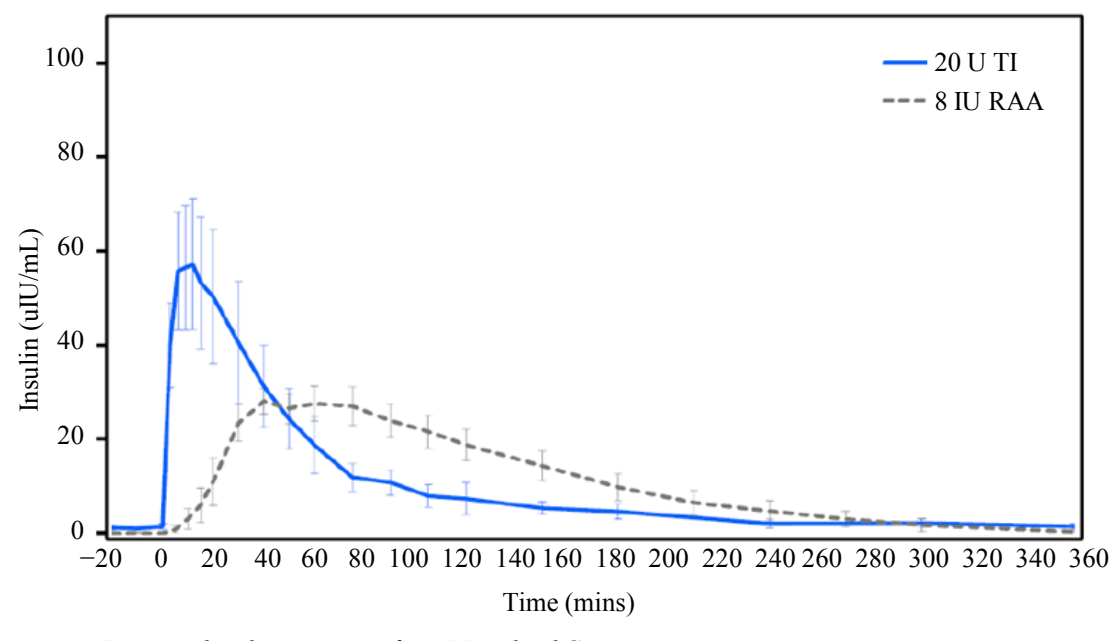

Reprinted with permission from Mannkind Corporation

Figure 1. Mean (SE) baseline-corrected TI concentration-time profile compared to a subcutaneously-injected RAIA.

be higher than that of injected insulin [20]. Bioavailability for the product varied, possibly due to patients' inhaler technique, but was shown to be approximately $21 \%$ to $35 \%$, compared with regular subcutaneous (SC) insulin [20] [21]. There is also evidence that the product clears more quickly than injected insulin, evaluated by a shorter time to reach the half-minimum serum concentration when compared with regular SC insulin [20].

\section{Technosphere Insulin-Efficacy and Safety}

\subsection{Efficacy}

Ten Phase 3 studies have been conducted to evaluate the efficacy and safety of TI. Early Phase 3 studies were limited by short study durations, inadequate dose titrations, and utilization of the MedTone inhaler device, which was later replaced by the current TI Gen2 inhaler. The application for approval to the FDA focused primarily on four Phase 3 studies, which had treatment durations of 16 weeks or longer and appropriate dose titration protocols [22]. Two were performed in patients with T1D (Studies 009 and 171) [23] [24] and two in patients with T2D (Studies 102 and 175) [25] [26].

Study 175 was a 24-week, double-blind, placebo-controlled, superiority study in 353 patients with T2D [19] [26]. Subjects were insulin naïve, inadequately controlled on OAD therapy, with baseline A1C levels $7.5 \%$ $10 \%$. Subjects continued background OAD therapy at stable doses and were randomized to either inhaled TI or inhaled placebo using the Gen2 inhaler device. Insulin and placebo doses were titrated during the first 12 weeks of the study using a pre-specified titration protocol and were kept stable for the last 12 weeks of the study. After 24 weeks of therapy, the mean reduction in A1C from baseline was significantly greater in the TI group compared to the placebo group $(-0.82 \%$ vs. $-0.42 \%, p<0.001)$ [19]. In addition, more patients achieved an A1C $\leq$ $7 \%$ in the TI group compared to the placebo group $(32.3 \%$ vs. $15.3 \%, \mathrm{p}<0.0005)$ [19]. The TI group showed a mean weight gain of $0.49 \mathrm{~kg}$ during the study compared to a $1.13 \mathrm{~kg}$ weight loss in the inhaled placebo group. The study has not been published so data is restricted to what is available with the prescribing information.

Study 102 was a 52-week, open-label, non-inferiority study that randomized 618 patients with T2D to either TI plus insulin glargine or a biphasic, pre-mixed rapid acting insulin analog (BPR 70/30) containing 70\% insulin aspart protamine suspension and 30\% insulin aspart [25]. The TI was delivered using an earlier inhaler device (MedTone) than the currently approved TI product which uses the Gen2 inhaler device. Enrollment criteria specified that subjects needed to be inadequately controlled on insulin with or without OAD the rapy, with baseline A1C levels $7 \%-11 \%$. Subjects that were randomized to TI plus insulin glargine received about half of their total daily dose as insulin glargine and half of their total daily dose as TI distributed across main meals and titrated incrementally based on self-monitoring blood glucose (SMBG). For subjects randomized to twice daily BPR 70/30, doses were adjusted based on fasting plasma glucose and glucose levels before dinner. All insulin doses were made at the discretion of the investigators. 
After 52 weeks of therapy, the mean reduction in A1C from baseline was similar between groups. The TI plus insulin glargine group achieved a reduction of $-0.68 \%$, which was non-inferior to the BPR 70/30 group which achieved a reduction of $-0.76 \%$ [25]. The between group difference was $0.07 \%(95 \% \mathrm{CI}-0.13$ to 0.27$)$ which met the pre-defined criteria for non-inferiority (upper $95 \%$ CI less than 0.4 ). The proportion of patients achieving an $\mathrm{A} 1 \mathrm{C} \leq 7 \%$ was also similar between subjects receiving TI plus insulin glargine and those on BPR 70/30 $(22 \%$ vs. $27 \%, p=0.2793)$. Changes in fasting glucose and post-prandial glucose values were also similar between groups. Weight gain was significantly lower in subjects receiving TI plus basal insulin compared to those receiving BPR 70/30 (0.9 kg vs. $2.5 \mathrm{~kg}, \mathrm{p}=0.0002)[25]$.

\subsection{Safety}

Similar to other insulin agents, hypoglycemia is the most common adverse effect (AE) seen with TI [19]. Rates of hypoglycemia in Phase 3 studies in T2D subjects are in Table 1. Rates of both severe and non-severe hypoglycemia were more common in patients with T2D taking TI compared to those taking inhaled placebo [19]. In the active comparator study, both severe and non-severe hypoglycemia events were less common in patients taking TI plus insulin glargine compared to patients taking BPR 70/30 [25].

Due to the inhaled route of delivery and concerns regarding the pulmonary safety of TI, subjects with active pulmonary disease, current smokers, and those with a history of chronic obstructive pulmonary disease (COPD) or asthma were excluded from Phase 3 studies. Pulmonary safety, including pulmonary function tests (PFTs) were evaluated consistently across all trials. The most common adverse effects associated with TI, other than hypoglycemia, were cough, throat pain and throat irritation [19] (Table 2). Overall, pooled respiratory AEs were higher in patients taking TI (45.2\%) compared to patients taking inhaled placebo (35.9\%) and patients taking comparator agents $(31.0 \%)$ [22]. Respiratory AEs leading to treatment discontinuation were similar between TI and inhaled placebo (4.6\% vs $2.4 \%$ ) but higher than non-inhaled comparators $(0.1 \%)$. In the Phase 3 clinical trials, cough occurred in about one quarter of patients receiving TI. The cough is likely due to the dry powder inhalation formulation and has been described as dry and transient, occurring most frequently in the first weeks of therapy.

Pooled data of clinical trials which excluded patients with chronic lung disease showed a small decline in $\mathrm{FEV}_{1}$ in patients taking TI [19]. The initial decline occurred in the first 3 months and persisted over the duration of the studies, but did not appear to worsen with continued use up to 2 years [19]. Mean differences in $\mathrm{FEV}_{1}$ decline between the TI and comparator groups were $-0.040 \mathrm{~L}$ at 3 months, $-0.043 \mathrm{~L}$ at 6 months, $-0.036 \mathrm{~L}$ at 9 months, $-0.038 \mathrm{~L}$ at 12 months, $-0.045 \mathrm{~L}$ at 18 months and $-0.045 \mathrm{~L}$ at 24 months [22]. To put this in perspective,

Table 1. Technosphere Insulin: Common Adverse Reactions (excluding hypoglycemia) in Patients with T2D [19].

\begin{tabular}{cccc}
\hline & Placebo $(\mathbf{n}=\mathbf{2 9 0})$ & TI $(\mathbf{n}=\mathbf{1 9 9 1})$ & Non-placebo comparator $(\mathbf{n}=\mathbf{1 3 6 3})$ \\
\hline Cough & $19.7 \%$ & $25.6 \%$ & $5.4 \%$ \\
Throat pain or irritation & $3.8 \%$ & $4.4 \%$ & $0.9 \%$ \\
Headache & $2.8 \%$ & $3.1 \%$ & $1.8 \%$ \\
Diarrhea & $1.4 \%$ & $2.7 \%$ & $2.2 \%$ \\
Productive cough & $1.0 \%$ & $2.2 \%$ & $0.9 \%$ \\
Fatigue & $0.7 \%$ & $2.0 \%$ & $0.6 \%$ \\
Nausea & $0.3 \%$ & $2.0 \%$ & $1.0 \%$ \\
\hline
\end{tabular}

$\mathrm{TI}=$ technosphere insulin.

Table 2. Incidence of Hypoglycemia in Phase 3 TI T2D Studies [22] [25] [26].

\begin{tabular}{|c|c|c|c|}
\hline Study & Treatment Arms & Severe hypoglycemia & Non-severe Hypoglycemia \\
\hline Trial 175 & $\begin{array}{c}\text { TI } \\
\text { Placebo }\end{array}$ & $\begin{array}{l}5.1 \% \\
1.7 \%\end{array}$ & $\begin{array}{l}67 \% \\
30 \%\end{array}$ \\
\hline Trial 102 (Rosenstock et al.) & $\begin{array}{c}\mathrm{TI}+\text { insulin glargine } \\
\text { BPR } 70 / 30\end{array}$ & $\begin{array}{c}4.3 \% \\
10 \%\end{array}$ & $\begin{array}{l}48 \% \\
69 \%\end{array}$ \\
\hline
\end{tabular}

$\mathrm{BPR}=$ biphasic pre-mixed rapid-acting insulin, $\mathrm{TI}=$ technosphere insulin. 
a $20 \%$ decrease of $\mathrm{FEV}_{1}$ would amount to approximately $-0.5 \mathrm{~L}$, depending on patient-specific factors.

There are some data evaluating TI in patients with underlying lung disease. A Phase 1, single-dose trial was conducted in 20 patients with COPD, matched to 20 control patients to assess the effects of a single dose of TI on lung function. Patients with COPD experienced a rapid decline in $\mathrm{FEV}_{1}$ that resolved gradually over 8 hours [22]. Similarly, a phase 1, single-dose study was conducted in 17 patients with asthma, matched to 13 healthy control patients to assess the effects of TI on lung function. After withholding bronchodilator therapy, patients were given 1 dose of TI. Patients with asthma experienced a mean decline in $\mathrm{FEV}_{1}$ of $12 \%$ after 15 minutes; those without asthma experienced a mean decline of 3.4\% after 15 minutes. Five patients with asthma (29\%) developed bronchoconstriction, wheezing, or an asthma exacerbation after receiving TI. Administering salmeterol prior to the TI dose resulted in no decline in $\mathrm{FEV}_{1}$ [22]. Finally, to evaluate the effects of smoking on TI treatment, a Phase 1, single-dose, euglycemic clamp study was conducted in 12 T2D patients who smoked and 12 non-smoking T2D patients as controls. The non-smoking group reached $\mathrm{T}_{\max }$ more quickly compared to the smoking group (12 vs. 20 minutes, $\mathrm{p}=0.010)$ but there were no significant differences in $\mathrm{C}_{\max }$ or AUC between groups [22].

In clinical trials of TI, two cases of lung cancer were observed in patients taking TI while no cases were observed in patients taking comparators. In both cases, the patient had a history of heavy tobacco use. Two additional cases of lung cancer were reported after completing of the clinical trial in non-smoking patients who had received TI [19].

Due to the risk of acute bronchospasm, TI is contraindicated in patients with chronic lung disease including COPD or asthma. TI is not recommended in patients who smoke or have smoked in the previous six months. PFTs should be conducted at baseline prior to initiating TI, after 6 months of use, and annually thereafter [19]. Patients who encounter an $\mathrm{FEV}_{1}$ decline of $\geq 20 \%$ from baseline should consider discontinuation [19]. The long term efficacy and safety of TI in patients with chronic lung disease has not been established.

\section{Patient Perspectives}

Patient perceptions regarding inhaled insulin therapy are important considerations, due to documented barriers with the use of subcutaneously injected insulin, and due to the failure of the first inhaled insulin product to succeed on the US market. The new product is markedly different than the previous inhaled insulin in several ways, with the most notable one being the inhaler's physical size (Figure 2). There have been a number of studies demonstrating better patient satisfaction with inhaled insulin compared to subcutaneous injections, with one study reaching a preference of 8:1 in favor of inhaled insulin [27]-[29].

An open-labeled, parallel-group, randomized, controlled, 12-week trial compared patients using either a mixed SC insulin $\left(2-3\right.$ injections/day) $(n=25)$ or inhaled insulin $\left(\right.$ Exubera $\left.^{\circledR}\right)$ used before meals with basal ultralente injected subcutaneously at night $(n=26)$ [28]. The Patient Satisfaction with Insulin Therapy Questionnaire was used to evaluate patient perceptions, and was completed by 47 patients ( 22 in the inhaled group, 25 in the SC injection group). The mean overall satisfaction improvement was significantly greater $(\mathrm{p}<0.05)$ in the inhaled insulin group $(31 \% ; 95 \%$ CI 14 - 50) compared with the SC insulin group (13\%, 95\% CI 7 - 19) [28].

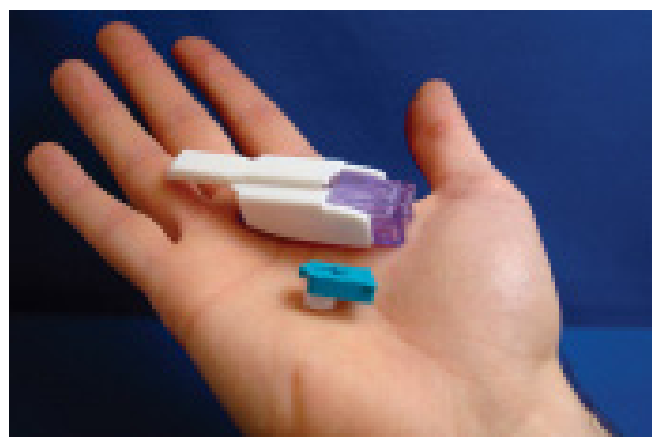

Used with permission from Mannkind Corporation

Figure 2. Picture of the Gen2 Technosphere ${ }^{\circledR}$ insulin inhaler device [36]. 
Peyrot and colleagues presented data evaluating health-related quality of life (HR-QOL) through the use of the standardized short-form 36 (SF-36) and Insulin Treatment Questionnaire in T2D patients [30]. Patients were randomized to receive either TI $(n=177)$, metformin with a secretagogue $(n=162)$, or a combination of TI with metformin and secretagogue $(n=169)$. [30] The authors reported an increase in treatment satisfaction after 12 weeks in both the TI arm $(p=0.003)$ and the TI plus oral therapies arm $(p<0.0001)$, compared with baseline ratings. These changes were statistically better than those reported in the metformin + secretagogue group $(\mathrm{p}=$ 0.0116 for TI alone, $\mathrm{p}=0.0009$ for TI with oral agents) [30].

Another study used a standardized HR-QOL questionnaire to ask 532 T2D patients about potential additional drug therapy options [31]. Initially, patients compared the option of SC insulin with alternative OAA options. During this phase, patients rejected the option of insulin $83 \%$ of the time. As a second phase, researchers added inhaled insulin as a potential option, and this dropped patients' resistance to insulin therapy down to $57 \%$. The paper concluded that while insulin therapy acceptance with T2D is low, that adding alternative delivery options may improve patient acceptance [31].

An internet survey was distributed to 1094 T2D patients in the US, where patients were instructed to rank potential advantages that inhaled insulin may have over SC injected insulin [32]. Patients ranked "avoiding postprandial hyperglycemia" and less "discomfort and inconvenience" as benefits most strongly related to evaluating and considering inhaled insulin therapy [32].

\section{Place in Therapy}

TI is a rapid-acting inhaled insulin indicated for use in adult patients with either T1D or T2D to improve glucose control [19]. Published efficacy and safety data in patients with T2D is limited, but indicate that TI lowers A1C significantly more than inhaled placebo and is non-inferior, when used with basal insulin, to biphasic, pre-mixed insulin. Pharmacokinetic studies show that TI has a faster onset and shorter duration of action compared to rapid-acting, subcutaneous insulin. This rapid-on, rapid-off PK profile could theoretically lead to better postprandial glucose profiles with less pronounced hyperglycemia and lower rates of delayed hypoglycemia [33]. More studies are needed to determine if these PK advantages translate to differences in clinically meaningful outcomes. Particularly, a head-to-head study comparing TI to rapid-acting insulin in the T2D patient population is needed.

One advantage of TI over current prandial insulin options is the inhaled route of delivery. TI may be a reasonable alternative to rapid acting insulins in patients who are resistant to self-administered subcutaneous injections. However, considering the available data, it is unclear where TI will fit within clinical treatment guidelines. Currently, in T2D treatment guidelines, prandial insulin is reserved for patients who have not achieved adequate glycemic control despite treatment with OADs and maximization of basal insulin [4] [5]. This suggests that those patients that are resistant to subcutaneous injections would likely still require basal insulin delivered by injection prior to initiating prandial insulin. Although TI could eliminate the need for injections prior to meals and reduce the number of total injections per day, it would likely not eliminate injections completely. It has been observed that for inhaled insulin to truly be a successful alternative to injections, formulation changes need to be implemented to allow for both basal and bolus insulin delivery [12].

While typically viewed advantageously over injectable insulin, the inhaled route of delivery carries its own potential barriers and disadvantages. Proper use of the inhaler device, including inhaler technique, correct dosing and correct utilization of dose cartridges requires adequate training and patient understanding. The average wholesale price of initial doses of TI (4 units before each meal) is $\$ 271.27$ for a 30-day supply, which is comparable to rapid-acting insulin analogs. [34] Cost implications for patients, however, will ultimately come down to formulary decision makers. The additional costs of routine PFTs as well as the availability of conducting these tests are important considerations and could prove to be significant barriers to TI therapy.

It has been observed that one key aspect to this product's success is the manufacturer's on-going support and marketing to both consumers and providers [35]. Survey data suggest that providers would consider this alternative method of insulin delivery, but reserve it for specific patient populations. More extensive pediatric safety and efficacy data would improve the uptake of inhaled insulin in this population.

\section{Conclusion}

TI offers a new rapid-acting insulin option with a novel delivery that targets post-prandial glucose and does not 
require subcutaneous injection. It has demonstrated superior effectiveness in lowering A1C compared to placebo and non-inferiority, when used in combination with basal insulin, compared to premixed, biphasic SC insulin. Pharmacokinetic studies suggest that TI may provide faster onset of action and shorter duration of action compared to rapid-acting insulin, which could potentially improve the postprandial glucose profile. However, this has not been demonstrated yet in a head-to-head trial in patients with T2D. TI may be a reasonable alternative to prandial insulin in patients who are resistant to administering injections.

\section{References}

[1] King, H., Aubert, R.E. and Herman, W.H. (1998) Global Burden of Diabetes, 1995-2025: Prevalence, Numerical Estimates, and Projections. Diabetes Care, 21, 1414-1431. http://dx.doi.org/10.2337/diacare.21.9.1414

[2] (2014) National Diabetes Statistics Report 2014. Atlanta, GA: Centers for Disease Control and Prevention, 2014, Accessed 16 March 2016. http://www.cdc.gov/diabetes/pubs/statsreport14/national-diabetes-report-web.pdf

[3] Defronzo, R.A. (2009) Banting Lecture. From the Triumvirate to the Ominous Octet: A New Paradigm for the Treatment of Type 2 Diabetes Mellitus. Diabetes, 58, 773-795. http://dx.doi.org/10.2337/db09-9028

[4] Inzucchi, S.E., Bergenstal, R.M., Buse, J.B., et al. (2015) Management of Hyperglycemia in Type 2 Diabetes, 2015: A Patient-Centered Approach: Update to a Position Statement of the American Diabetes Association and the European Association for the Study of Diabetes. Diabetes Care, 38, 140-149. http://dx.doi.org/10.2337/dc14-2441

[5] Garber, A.J., Abrahamson, M.J., Barzilay, J.I., et al. (2015) Aace/Ace Comprehensive Diabetes Management Algorithm 2015. Endocrine Practice: Official Journal of the American College of Endocrinology and the American Association of Clinical Endocrinologists, 21, 438-447.

[6] Hamaty, M. (2011) Insulin Treatment for Type 2 Diabetes: When to Start, Which to Use. Cleveland Clinic Journal of Medicine, 78, 332-342. http://dx.doi.org/10.3949/ccjm.78a.10051

[7] Rolla, A.R. (2011) Progression of Type 2 Diabetes and Insulin Initiation. Journal of the National Medical Association, 103, 241-246. http://dx.doi.org/10.1016/S0027-9684(15)30296-0

[8] Polonsky, W.H., Fisher, L., Guzman, S., Villa-Caballero, L. and Edelman, S.V. (2005) Psychological Insulin Resistance in Patients with Type 2 Diabetes: The Scope of the Problem. Diabetes Care, 28, 2543-2545. http://dx.doi.org/10.2337/diacare.28.10.2543

[9] Peyrot, M., Rubin, R.R., Lauritzen, T., et al. (2005) Resistance to Insulin Therapy among Patients and Providers: Results of the Cross-National Diabetes Attitudes, Wishes, and Needs (DAWN) Study. Diabetes Care, 28, 2673-2679. http://dx.doi.org/10.2337/diacare.28.11.2673

[10] Kunt, T. and Snoek, F.J. (2009) Barriers to Insulin Initiation and Intensification and How to Overcome Them. International Journal of Clinical Practice, 164, 6-10. http://dx.doi.org/10.1111/j.1742-1241.2009.02176.x

[11] Zambanini, A., Newson, R.B., Maisey, M. and Feher, M.D. (1999) Injection Related Anxiety in Insulin-Treated Diabetes. Diabetes Research and Clinical Practice, 46, 239-246. http://dx.doi.org/10.1016/S0168-8227(99)00099-6

[12] Rashid, J., Absar, S., Nahar, K., Gupta, N. and Ahsan, F. (2015) Newer Devices and Improved Formulations of Inhaled Insulin. Expert Opinion on Drug Delivery, 12, 917-928. http://dx.doi.org/10.1517/17425247.2015.990436

[13] Siekmeier, R. and Scheuch, G. (2008) Inhaled Insulin—Does It Become Reality? Journal of Physiology and Pharmacology, 59, 81-113.

[14] Cefalu, W.T. (2004) Concept, Strategies, and Feasibility of Noninvasive Insulin Delivery. Diabetes Care, 27, $239-246$. http://dx.doi.org/10.2337/diacare.27.1.239

[15] Bailey, C.J. and Barnett, A.H. (2007) Why Is Exubera Being Withdrawn? BMJ, 335, 1156-1156. http://dx.doi.org/10.1136/bmj.39409.507662.94

[16] Heinemann, L. (2008) The Failure of Exubera: Are We Beating a Dead Horse? Journal of Diabetes Science and Technology, 2, 518-529. http://dx.doi.org/10.1177/193229680800200325

[17] Mannkind Corporation (2014) Briefing Document-Endocrinology \& Metabolic Drug Advisory Committee. Mannkind Corporation, Valencia.

http://www.fda.gov/downloads/advisorycommittees/committeesmeetingmaterials/drugs/endocrinologicandmetabolicdr ugsadvisorycommittee/ucm390865.pdf

[18] Angelo, R., Rousseau, K., Grant, M., Leone-Bay, A. and Richardson, P. (2008) Technosphere (R) Insulin: Defining the Mechanism of Action. Diabetes, 57, A128.

[19] Potocka, E., Hovorka, R., Baughman, R., et al. (2009) Technosphere Insulin Suppresses Endogenous Glucose Production Earlier than a Rapid-Acting Analogue (Lispro) and an Inhaled Insulin (Exubera (R)). Diabetologia, 52, S374.

[20] Sanofi US (2014) Afrezza Package Insert. http://products.sanofi.us/afrezza/AFREZZA.pdf 
[21] Rave, K., Potocka, E., Boss, A.H., Marino, M., Costello, D. and Chen, R. (2009) Pharmacokinetics and Linear Exposure of AFRESA Compared with the Subcutaneous Injection of Regular Human Insulin. Diabetes, Obesity \& Metabolism, 11, 715-720. http://dx.doi.org/10.1111/j.1463-1326.2009.01039.x

[22] Steiner, S., Pfutzner, A., Wilson, B.R., Harzer, O., Heinemann, L. and Rave, K. (2002) Technosphere/Insulin—Proof of Concept Study with a New Insulin Formulation for Pulmonary Delivery. Experimental and Clinical Endocrinology \& Diabetes, 110, 17-21. http://dx.doi.org/10.1055/s-2002-19989

[23] Kapsner, P.B.R., Rendell, M., Howard, C., Boss, A., Chang, P., Kramer, D. and Richardson, P. (2009) Comparative Efficacy and Safety of Technosphere Insulin and a Rapid-Acting Analog both Given with Glargine in Subjects with T1 DM in a 52-Week Study. Diabetologia, 52, Poster \#982.

[24] Bode, B.W., McGill, J.B., Lorber, D.L., Gross, J.L., Chang, P.-C. and Bregman, D.B. (2015) Inhaled Technosphere Insulin Compared with Injected Prandial Insulin in Type 1 Diabetes: A Randomized 24-Week Trial. Diabetes Care.

[25] Rosenstock, J., Lorber, D.L., Gnudi, L., Howard, C.P., Bilheimer, D.W., Chang, P.-C., et al. (2010) Prandial Inhaled Insulin plus Basal Insulin Glargine versus Twice Daily Biaspart Insulin for Type 2 Diabetes: A Multicentre Randomised Trial. Lancet, 375, 2244-2253. http://dx.doi.org/10.1016/S0140-6736(10)60632-0

[26] MKC-TI-175 (2013) Trial 175: A Phase 3, Multicenter, Double-Blind, Placebo-Controlled, Randomized, Clinical Trial Evaluating the Efficacy and Safety of Prandial Technosphere ${ }^{\circledR}$ Insulin Inhalation Powder versus Technosphere ${ }^{\circledR}$ Inhalation Powder (Placebo) in Insulin Naïve Subjects with Type 2 Diabetes Mellitus Poorly Controlled with Oral Antidiabetic Agents over a 24-Week Treatment Period. Unpublished Manuscript.

[27] McMahon, G.T. and Arky, R.A. (2007) Inhaled Insulin for Diabetes Mellitus. The New England Journal of Medicine, 356, 497-502. http://dx.doi.org/10.1056/NEJMct063533

[28] Cappelleri, J.C., Cefalu, W.T., Rosenstock, J., Kourides, I.A. and Gerber, R.A. (2002) Treatment Satisfaction in Type 2 Diabetes: A Comparison between an Inhaled Insulin Regimen and a Subcutaneous Insulin Regimen. Clinical Therapeutics, 24, 552-564. http://dx.doi.org/10.1016/S0149-2918(02)85131-1

[29] Sadri, H., MacKeigan, L.D., Leiter, L.A. and Einarson, T.R. (2005) Willingness to Pay for Inhaled Insulin: A Contingent Valuation Approach. Pharmacoeconomics, 23, 1215-1227. http://dx.doi.org/10.2165/00019053-200523120-00006

[30] Peyrot, M. and Rubin, R.R. (2009) Patient Reported Outcomes in Adults with Type 2 Diabetes Using Mealtime AFRESA (Inhaled Technosphere Insulin) or Metformin + Secretagogue or both (Abstract 552-P). Diabetes, 58, A148.

[31] Petrak, F., Herpertz, S., Stridde, E. and Pfutzner, A. (2013) Psychological Insulin Resistance in Type 2 Diabetes Patients Regarding Oral Antidiabetes Treatment, Subcutaneous Insulin Injections, or Inhaled Insulin. Diabetes Technology \& Therapeutics, 15, 703-711.

[32] Peyrot, M. and Rubin, R.R. (2011) Perceived Medication Benefits and Their Association with Interest in Using Inhaled Insulin in Type 2 Diabetes: A Model of Patients' Cognitive Framework. Patient Preference and Adherence, 5, 255-265. http://dx.doi.org/10.2147/PPA.S18799

[33] Klonoff, D.C. (2014) Afrezza Inhaled Insulin: The Fastest-Acting FDA-Approved Insulin on the Market Has Favorable Properties. Journal of Diabetes Science and Technology, 8, 1071-1073. http://dx.doi.org/10.1177/1932296814555820

[34] Afrezza. Red Book Online, Micromedex 2.0. Thompson Reuters, Greenwood Village. Accessed 16 March 2016. http://www.micromedexsolutions.com/micromedex2/librarian/ND T/evidencexpert/ND PR/evidencexpert/CS/5F713E ND AppProduct/evidencexpert/DUPLICATIONSHIELDSYNC/7E2279/ND PG/evidencexpert/ND B/evidencexpert ND_P/evidencexpert/PFActionId/redbook.FindRedBook?navitem=topRedBook\&isToolPage=true

[35] Al-Tabakha, M.M. (2015) Future Prospect of Insulin Inhalation for Diabetic Patients: The Case of Afrezza versus Exubera. Journal of Controlled Release, 215, 25-38. http://dx.doi.org/10.1016/j.jconrel.2015.07.025

[36] Mannkind Corporation (2016) Company Media Room. http://www.mannkindcorp.com/news-and-events-media-room-photos.htm 